\title{
Comparison of the Stress, Sexual Disfunction, and Mental Happiness Coping Strategies in Two Groups of Normal Married Women and Women with Marital Conflicts
}

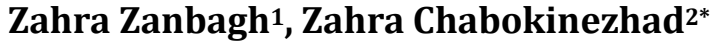 \\ ${ }^{1}$ Department of General Psychology, Yazd Branch, Islamic Azad University, Yazd, Iran \\ ${ }^{2}$ Department of Psychology, Yazd Branch, Islamic Azad University, Yazd, Iran \\ Email: *zahrachabokynegad@yahoo.com
}

How to cite this paper: Zanbagh, Z., \& Chabokinezhad, Z. (2018). Comparison of the Stress, Sexual Disfunction, and Mental Happiness Coping Strategies in Two Groups of Normal Married Women and Women with Marital Conflicts. Creative Education, 9, 292-307.

https://doi.org/10.4236/ce.2018.92020

Received: January 10, 2018

Accepted: February 23, 2018

Published: February 26, 2018

Copyright (c) 2018 by authors and Scientific Research Publishing Inc. This work is licensed under the Creative Commons Attribution International License (CC BY 4.0).

http://creativecommons.org/licenses/by/4.0/

\section{(c) (i) Open Access}

\begin{abstract}
In the era that rapid and unpredictable changes have happened in human life, the family is still one of the sources that have a prominent role in protecting people, their social and emotional support, but data from past decades indicate an increase in divorce rates both in the world and in Iran. The present research aimed to compare coping strategies with stress, sexual disfunction, mental happiness in two groups of normal married women and women with marital conflicts. The research employed a causal-comparative method. The statistical population included all normal married women and women with marital conflicts who referred to counseling centers in Yazd city in 2016-2017. To this end, 150 women ( 75 normal married women and 75 women with marital conflicts) were selected using available sampling method. They completed the Lazarus and Fulkman (1985), Female Sexual Function Index (ROS) (2000), Panas Mental Happiness (1988) questionnaires. Data were analyzed using ANOVA and Independent T-test in SPSS software. The findings showed that there is a difference between strategies for coping with stress, sexual disfunction, and mental happiness in both married women and women with marital conflicts.
\end{abstract}

\section{Keywords}

Stress Coping Strategies, Sexual Disfunction, Mental Happiness, Marital Conflicts

\section{Introduction}

People experience many changes throughout their lives. The most important 
developments are marriage, job selection, having child, and finally the abandonment of the house by children and retirement. The occurrence of any of these changes can be caused by conflict and a problem within the family (Shahverdi et al., 2015). Several definitions of marital conflict are presented. Systemic therapists consider marital conflict as a struggle to seize bases and sources of power and eliminate each other's privileges (Ahmadi et al., 2016). Disagreement, difference, or incompatibility among spouses will arouse conflicts (Markman \& Halford, 2005). Fowers and Olson (1992) also find conflicting wives who are dissatisfied with their spouse's habits and personality and have a communication problem in a variety of contexts. In other words, conflict arises when one's actions and behavior interfere with other acts and behaviors of the others. In addition, when the two individuals get closer, the conflict force increases (Shahverdi et al., 2015). Another factor that influences the strength and stability of families is mental happiness. A society can move towards its transcendent and ideal goals when the happiness is the continuous experience of its members, because happiness plays an important role in improving physical and mental health. A person who is happier is more relaxed and more secure, easier to make decisions, with more decent work, and more involvement and ultimately has a more satisfying life (Pressman \& Cohen, 2005). For this reason, today, studies on happiness and its related factors are among the most important priorities of psychology.

On the other hand, the marital relationship is one of the most intimate and most private forms of human communication, which is one of the innate human needs. Having a relationship with a spouse can be a source of comfort, support, and pleasure for everyone, while this relationship can sometimes be a source of anxiety, frustration, and dissatisfaction (Zeinali, 2014). Various factors are involved in marital satisfaction, such as the quality of marriage relationships, marriage, communication practices, couples' character, and ways to deal with marital problems that are well known in this field (Patrik et al., 2007). Another factor is the sexuality and sexual issues of couples. Sexuality is one of the key elements of women's global psychological well-being. Sexual disfunction also includes problems that affect the person's sexual desire, arousal and ability to reach the orgasm, and this type of problems is also common during sexual intercourse. In other words, the definition of sexual disfunction is the destruction of one or more stages of the cycle of sexual responses, as well as the presence of pain associated with intercourse, which causes tangible distress and interpersonal problems according to DSM-IV-TR. Disfunction is widely defined as the inability to fully enjoy sexual intercourse. Specific sexual disfunction is disorders that interfere with a complete sexual response. These disorders create problems for enjoyment or sexual intercourse, which rarely endangers the physical health. However, it can cause psychological damage, depression, anxiety, weakness, and inefficiency (Rajabi \& Ghaffari, 2008).

It should also be noted that the family is the most fundamental social organization and is the main social component. Achieving a healthy community de- 
pends on the health of the family and the realization of a healthy family, provided that they have mental health and have a good relationship with each other (Karami et al., 2012). Various factors are involved in this case one of which is strategies for coping with stress. Stress means pressure and force, and any stimulus that creates tension in humans is called stressor (Sharif \& Yousefi, 2015). Lazarus and Folkman (1984) defined coping strategies as a set of behavioral and cognitive responses aimed at minimizing tension stresses. Initial adaptations to the coping process differentiate the three main styles: problem-focused coping style, the direct feature of which is to reduce stress or increase stress management skills; avoidant-focused coping style that is characterized by avoiding exposure to the stressor and coping styles. The emotional-focused feature is the cognitive strategies that delay or eliminate the stressor by giving new names and meanings (Besharat et al., 2008). In contrast to different coping responses, people give rise to different coping responses in the face of stressful situations, the characteristics and characteristics of the situation, especially the stressor's controllability (Sharif \& Yousefi, 2015). Therefore, the use of various effective coping methods (problem-focused) and inefficiency (emotional-focused) have different consequences on physical and mental health of individuals (Sarafino, 2002).

Studies have shown that conflicted relationships lead to problems in physical and mental health. In addition, there is a relationship between marital problems, marital conflicts, marital adjustment and depression symptoms (Beach et al., 1998; Soudani et al., 2009). Conflict in human relationships is inevitable (Shahverdi et al., 2015) and disagreement in any marital relationship is natural. Studies have shown that there is not much conflict between couples who can manage conflicts in a positive way and have the ability to solve them (Siffert \& Schwarz, 2010). However, most individuals psychologically experience conflict infinitely stressful (Halford, 2001). It is related to dissatisfaction and incompatibility, which means that increasing conflict in couples increases the incompatibility and dissatisfaction. In addition, these problems are considered to be divorce and separation grounds (Soudani et al., 2009), and the relationship between marital conflict and marital satisfaction has a long history of research (Claire, Dush, \& Taylor, 2011). Typically, disturbed couples exhibit less communication skills than non-disturbed couples, and do not have a good view of their relationship. These couples are more likely to avoid each other than to solve it through negotiation (Carr, 2000). In addition, the conflict between family members is harmful to the unity and integrity of the family and is associated with psychological problems such as depression and anxiety (Shahverdi et al., 2015); therefore, it is an important predictor of health (Troxel, 2006).

On the other hand, the happiness of the community is one of the most influential factors in economic, cultural, social and political development, reducing family disputes and divorce and increasing the amount of desire and willingness to study, conflict in work and production. Therefore, the happiness and identification of factors associated with happiness are very important. This issue has 
always been considered by scholars in recent years and since it is possible to regard happiness as a cultural-dependent variable, its study in each society can be of special importance (Grossifarshi et al., 2006).

Stress and life crisis are threats to physical and mental health that are inevitable in everyday life, but how to deal with them is important. Recent researches in this field have shown that the type of coping strategies used by the individual not only affects psychological well-being but also affects the physical well-being (Pico, 2001). Incorrect coping strategies lead to an increase in the burden of stress and its consequences, and suffering from these symptoms is a combination of mental and emotional disorders (AghaYousefi, 2011). Therefore, coping strategies are one of the variables widely discussed in the framework of the psychology of health (Sharif \& Yousefi, 2015).

Generally, given the fact that a healthy family usually handles healthy people and an unhealthy family will cause many problems at the community level, social problems will increase day by day if efforts are not done to improve the family (Satir, 1967). Therefore, considering the importance of the subject and considering the theoretical foundations and the importance of strategies for coping with stress, sexual disfunction and mental happiness in marital conflicts and the lack of research felt in this regard within the country. Therefore, the present study seeks to find out strategies for coping with stress, sexual disfunction, and mental happiness in two groups of normal married women and women with different marital conflicts. Accordingly, the research hypothesis is:

There is a significant difference between strategies for coping with stress, sexual disfunction, and mental happiness in both married women and women with marital conflicts.

In order to confirm this hypothesis, ordinary married women and women with marital conflicts who referred to Yazd counseling centers in the years 1969-96 were examined. About 75 normal married women and 75 women with marital conflicts were selected. They completed the Lazarus and Fulkman (1985), Female Sexual Function Index (ROS) (2000), Panas Mental Happiness (1988) questionnaires (see Appendixes 1-3). The findings showed that there is a difference between strategies for coping with stress, sexual disfunction, and mental happiness in both married women and women with marital conflicts.

\section{Materials and Methods}

This research is causal-comparative in terms of its implementation, and the method of this research is descriptive because of the lack of manipulation on the variables in this research. The population of this study was all normal married women and women with marital conflicts who referred to counseling centers in Yazd in 2016-2017. According to the consultation centers, if the number of marital conflicts referred to counseling centers in Yazd is 100, the sample size is about 75 from Cochran formula. Thus, the sample included 150 women (75 normal married women and 75 marital conflicts) referring to counseling centers in Yazd, which was obtained through available sampling. One of the criteria for 
choosing these people was to be consent to participate in the study. Some participants refused to continue to participate in the study for any reason were excluded from the sample. The following questionnaires were used to collect data:

The Ways of Coping Questionnaire (WCQ) by Lazarus and Folkman: this questionnaire is based on the Lazarus and Folkman (1986) theory of stress. In their view, our interpretation of our events is more important than events itself. They believe that individual perception is one of the situations that determine its severity. Accordingly, a questionnaire of 66 items was designed. Scoring the questionnaire of coping methods is done in two ways: raw and relative. The choice of which scoring method should be performed depends on the information that the researcher seeks to do (Rostami et al., 2013). Raw scores describe the coping effort for each of the eight types of coping. While relative scores describe the proportion of the effort that has been made in each type of coping. In both methods, individuals scramble for each substance on a scale of Likert's four variants, which shows the frequency of each strategy in this form. This test examines eight coping styles that are divided into two types of problem-focused and emotional-focused. Lazarus and Fulkman (1986) reported internal consistency of 0.66 to 0.79 for each of the coping styles. In this research, Rostami (2012) obtained a Cronbach alpha of 0.87 .

Marital Conflict Questionnaire (R-MCQ): Marital Conflict Questionnaire is a 54-item questionnaire designed to measure marital conflicts based on the clinical experience of Sanaei et al. (2009). Consultants and other clinicians can use this questionnaire to measure the marital conflicts. For each question, there are five options that are assigned to 1 to 5 points. The maximum total score of the questionnaire is 270 and at least 54 . Cronbach's alpha for the whole questionnaire was obtained on a 270 -member group of 0.96 . In addition, this questionnaire has a good reputation. In the test content analysis stage, no questions were eliminated after performing the preliminary tests and calculating the correlation of each question with the whole questionnaire and its scales, due to the correlation of the questions (Sanaei et al., 2009). In this study, internal consistency (by Cronbach's alpha method) for the total scale of this questionnaire was 0.98 .

Panas Mental Happiness Questionnaire (PANAS): This questionnaire was first created by Watson et al. (1988) as the Positive Affection Scale and Negative Affection, which later became known as the Happiness Scale by adding a total satisfaction scale of life. Subjects on a 5-point scale from 1 (very low) to 5 (very high) show the feeling of each of the 10 negative emotional states and each of the 10 positive emotional states in general felt. Davari (2013) used the views of the supervisor professor and several experts working in this field to determine the validity and confirmation that the listed questions and items are suitable for measuring the desired goals. After collecting comments and reviewing the suggestions of these people and discussing the questionnaire, the questionnaire was formulated and its validity was confirmed. Bakhshipour and Dejkam (2005) in 
Iran confirmed the factor structure of the questionnaire and calculated its alpha coefficient for each subscale as much as 0.87 .

\section{Female's Sexual Function Index (FSFI)}

Females' Sexual Performance Index is a measure used to measure female sexual function. This scale was developed by Rosen et al. (2000) and it is validated in a group of women with sexual anxiety disorder. The questionnaire, with 19 questions, assesses women's sexual function in six areas: desire, Arousal stimulation, Lurication, orgasm, satisfaction, and sexual pain. The mentioned questionnaire has been used in many studies outside the country and it has shown a high degree of internal consistency and reliability. Studies have shown a significant difference between the scores of the patients and the control group in each of the six domains. Considering the high scores and due to the shortness of the questionnaire, it seems that the female sexual function index is an appropriate tool for measuring sexual performance. Cronbach's alpha coefficient of sexual performance index has been reported in Besharat, Khajavi and Porkhaghan (2012). In addition, the internal consistency of the female sexual function questionnaire was reported as much as 0.91 (Kraskian Mojmari, \& Kib Elahi, 2014).

\section{Results}

Table 1 shows the descriptive indexes of variables. As the mean of groups shows, the average of problem-focused strategies and happiness in women without conflicts is more than conflicting women and the average of sexual quality in women with conflict is lower.

In order to investigate the research hypothesis, initially the hypotheses of variance analysis are evaluated. The first is to check whether the data is normal. To test the normal distribution of scores in pre-test and post-test, Shapiro-Wilk test was used (Table 2).

Usually, if the significance level in the Shapiro-Wilk test is more than 0.05, then data can be assumed with high normal confidence; Levin's test was used to examine the homogeneity assumption of variances. The results of this test are as follows (Table 3).

After confirmation of the hypotheses, one-way ANOVA was used to investigate the research hypothesis. The results of table number show that the $\mathrm{F}$ value of emotional-focused, sexual disfunction, and happiness is significant. Therefore, there is a significant difference between emotional-focused, sexual disfunction, and happiness in both married women and women with marital conflicts.

According to Table 4, there is a significant difference between strategies for coping with stress, sexual disfunction, and happiness in both groups of normal married women and women with marital conflicts.

\section{Discussion}

The present study aimed to compare the strategies of coping with stress, sexual 
Table 1. Descriptive indexes of research variables.

\begin{tabular}{cccccc}
\hline & Variables & Minimum & Maximum & Mean & Standard deviation \\
\hline & Emotional-focused strategy & 31 & 85 & 58.52 & 81.12 \\
Without conflicts & Problem-focused strategy & 26 & 72 & 171.51 & 131.11 \\
& Sexual disfunction & 37 & 85 & 17.68 & 86.9 \\
& Happiness & 37 & 84 & 19.59 & 95.7 \\
\hline \multirow{3}{*}{ With conflicts } & Emotional-focused strategy & 47 & 75 & 52.58 & 49.7 \\
& Problem-focused strategy & 25 & 65 & 20.48 & 24.9 \\
& Sexual disfunction & 18 & 60 & 77.37 & 67.10 \\
\hline
\end{tabular}

Table 2. Shapiro-Wilk test to examine the normal distribution of scores in research variables.

\begin{tabular}{cccc}
\hline Variable & Statistics & Degrees of freedom & Significance level \\
\hline Emotional-focused strategy & 0.98 & 77 & 0.718 \\
Problem-focused strategy & 0.92 & 77 & 0.391 \\
Sexual disfunction & 0.981 & 77 & 0.101 \\
Happiness & 0.955 & 77 & 0.233 \\
\hline
\end{tabular}

Table 3. Homogeneity analysis of variables for research variables.

\begin{tabular}{ccccc}
\hline & Levine's statistics & $\begin{array}{c}\text { First degree of freedom } \\
\text { (numerator) }\end{array}$ & $\begin{array}{c}\text { Second degree of freedom } \\
\text { (denominator) }\end{array}$ & Significance level \\
\hline Emotional-focused strategy & 0.38 & 1 & 78 & 0.84 \\
Problem-focused strategy & 0.78 & 1 & 78 & 0.34 \\
Sexual disfunction & 0.019 & 1 & 78 & 0.786 \\
Happiness & 1.42 & 1 & 78 & 0.485 \\
\hline
\end{tabular}

Table 4. One-way ANOVA results to compare strategies for coping with stress, sexual disfunction, and happiness in both married women and women with marital conflicts.

\begin{tabular}{|c|c|c|c|c|c|c|}
\hline Indicators & Source of change & Sum of squares & Df & Mean of squares & $\mathrm{F}$ & Significance level \\
\hline \multirow{3}{*}{$\begin{array}{c}\text { Emotional-focused } \\
\text { strategy }\end{array}$} & Intergroup & 676.895 & 1 & 676.895 & 5.945 & 0.017 \\
\hline & In group & 8538.923 & 75 & 113.852 & & \\
\hline & Total & 9215.818 & 76 & & & \\
\hline \multirow{3}{*}{$\begin{array}{l}\text { Problem-focused } \\
\text { strategy }\end{array}$} & Intergroup & 175.786 & 1 & 175.786 & 1.672 & 0.2 \\
\hline & In group & 8198.164 & 78 & 105.105 & & \\
\hline & Total & 837,395 & 79 & & & \\
\hline \multirow{3}{*}{ Sexual disfunction } & Intergroup & $18,473.47$ & 1 & $18,473.472$ & 175.238 & 0.001 \\
\hline & In group & 8222.73 & 78 & 105.420 & & \\
\hline & Total & $26,696.2$ & 79 & & & \\
\hline \multirow{3}{*}{ Happiness } & Intergroup & 2056.664 & 1 & 2056.664 & 18.961 & 0.001 \\
\hline & In group & 8460.336 & 78 & 108.466 & & \\
\hline & Total & 10,517 & 79 & & & \\
\hline
\end{tabular}


disfunction, and mental happiness in two groups of normal married women and women with marital conflicts. According to Table 4, there is a significant difference between strategies for coping with stress, sexual disfunction, and mental happiness in both normal married women and women with marital conflicts. The results of this research are indirectly corresponded with Navabinejad et al. (2009), Bagheri et al. (2010), Alipour et al. (2010), Amirimajd and Zarimoghadam (2010), AliAkbariDehkordi (2010), Sheikholeslami et al. (2011), Shirazi et al. (2015), Karimi et al. (2016), Sepehrian Azar et al. (2016). In explaining these results, it can be argued that Lazarus and Folkman (1984) defined coping strategies as a set of behavioral and cognitive responses aimed at minimizing stress-strain situations. The excitement and physiological excitement caused by tension situations is very unpleasant, and this suffering induces a person to relieve it. The emotional-focused coping is a style, in which the individual focuses on himself and does his best to reduce unpleasant feelings, such as anger and upset, mental activity, loneliness, and depression and the problem-focused coping style refers to behaviors that are used to solve a problem, rebuilding the problem cognitively or attempting to change the stressor position. Problem-focused behaviors include searching for more information about the problem and prioritizing and sorting steps for problem solving.

In this study, there was a significant difference between the emotional-focused strategies in the two groups of normal married women and women with marital conflicts According to the second finding, emotional-focused strategies were more controversial in the group of women with conflict. As HosseiniSedeh and FathiAshtiani (2011) state that women who have marital conflicts are more likely to use emotional strategies than emotional coping strategies, which claims Confrontation, avoidance, escape-avoidance, and self-restraint are more controversial in women. In explaining this finding, it can be said that marital conflicts in married women are due to the heterogeneity of the husband and wife in the type of needs and their method of satisfaction, elf-regulation, disputes, behavioral schemas, and irresponsible behavior towards marital relationships and marriage. The conflict process is created when one of the parties perceives the relationship. The other party opposes some of hislher favorite issues. Therefore, the conflict occurs when something provides satisfaction to the person, while the same thing leads to deprivation for the other one. Therefore, these individuals offer aggressive attempts to change the position and extent of hostility and danger, and try to regulate the emotions and actions of the individual, so that women with marital conflicts use the emotional-focused strategies more.

In the following explanation, which shows that women without marital conflicts use problem-focused coping styles, which are seeking social support, accountability, planned problem-solving and positive re-evaluation, it can be said that according to the results of those who do not have conflicts in marital life and live in peace prefer to use problem-focused strategies and accept their role in the problem and always strive to put everything in the right place. These mar- 
ried women make thoughtful thought-provoking efforts to change their position and create a positive meaning by focusing on personal growth.

The next results showed that women with marital conflicts have more sexual disfunction and women without any conflict experience better sexual quality. Sexuality is an important element of women's general psychological well-being. According to Vermillion and Holmes (1997), sexual disfunction is not merely personal and interpersonal stress but also associated with medical illnesses and psychosocial problems of women who are significantly affecting their health. Women's sexual problems are the result of several factors that can affect their mental well-being and their health, including those that affect the person's sexual desire, arousal and ability to reach orgasm. In addition, these types of problems lead to pain during sexual intercourse.

Disfunction is widely defined as the inability to fully enjoy sexual intercourse. Specifically, sexual disfunctions are the disorders that interfere with a complete sexual response. These disorders create problems for enjoyment or sexual intercourse, causing psychological injuries, depression, anxiety, and feeling of weakness and inefficiency. Therefore, women with marital conflicts more experience sexual disfunctions such as disturbance in desire, arousal, orgasmic disorders, and pain disorders.

In the case of mental happiness, there was a significant difference between the two groups of normal married women and women with marital conflicts. According to Lyubomirsky (2001), happiness is defined based on direct ratings of individuals for their level of happiness, the amount of positive and negative long-term emotions, or the level of satisfaction with life. Mental happiness involves the emotional element (in other words, the experience of almost positive emotional affairs and almost negative emotions) and the cognitive element (in other words, life satisfaction or overall assessment of personal life). Therefore, a happy person is one who has many positive emotions, low negative emotions and experiences a lot of life satisfaction.

\section{Conclusion}

Variables such as parenting methods, recreational activities, marriage, divorce, serious disabilities, various personality traits, etc. are all factors that have been investigated by researchers in various researches as factors affecting happiness. In general, it can be concluded that happiness is a hypothetical instrument that is primarily involved in a set of external factors and variables, and secondly, internal variables such as cognitive factors (how to change and explain the individual of events) play an essential role in happiness. Therefore, married women without conflict increase their interest, cheerfulness, enthusiasm and pride, because the family without conflict is the focal point for security and tranquility, the marriage and comfort of man and woman, and people seeking to have a happy life in their family.

The main limitation of this research was the lack of cooperation between 
counseling centers and the researcher. Another limitation of the study is the use of subjective indicators with less objectivity to assess the variables of research (strategies for coping with stress, sexual disfunction, and mental happiness). If it was possible to assess these indicators, for example, by examining the participants' behavior or getting a report from people in close contact with them, such as their family members, it would naturally have the potential to deliver significant results.

According to the findings of this study, it is suggested that semi-experimental research and the impact of new approaches on reducing marital conflicts and other family-related variables, such as attachment and structural characteristics of the family, and so on in married women with and without conflicts should be examined and solutions should be adopted to reduce problems. The use of research findings by counselors and psychologists in counseling centers and the use of research results as premarital workshops are also a practical application of this research.

\section{References}

AghaYousefi, A. (2011). The Relationship of Coping Methods and Signs of Chronic Stress Using Medicine and Materials in Veterans of Qom. Veterans Medicine, 4, 24-33.

Ahmadi, Z., Ahmadi, S. A., \& Fatehizadeh, M. S. (2016). The Effect of Paired Therapy on Short-Term Relationship between Couples' Communication Patterns. Quarterly Journal of Family Studies, 2, 105-117.

AliAkbariDehkordi, M. (2010). Sexual Function of Women with Marital Adjustment. Journal of Behavioral Sciences, 4, 199-206.

Alipour, A., Hashemi Nosrat, T., BabaPoor Khiruddin, J., \& Toosi, F. (2010). The Relationship between Coping Strategies and Happiness of Students. New Psychological Research (Psychology, University of Tabriz), 5, 71-86.

Amirimajd, M., \& Zarimoghadam, F. (2010). Happiness and Marital Satisfaction Relationship among Employed Cultural Women and Housewives in Arak. Behavioral Sciences, 2, 9-21.

Bagheri, N., Ahadi, H., \& Lotfikashani, F. (2010). The Relationship between Coping Styles and Family Atmosphere with Happiness. Psychological Research, 2, 21-33.

Bakhshipour, A., \& Dejkam, M. (2005). Confirmatory Factor Analysis of Positive and Negative Affect Scale. Journal of Psychology, 36, 351-365.

Beach, S. R. H., Fincham, F. D., \& Katz, J. (1998). Marital Therapy in the Treatment of Depression: Toward a Third Generation of Outcome Research. Clinical Psychology Review, 18, 635-661. https://doi.org/10.1016/S0272-7358(98)00023-3

Besharat, M. A., Khajavi, Z., \& Pourkhaghan, F. (2012). The Role of Alexithymia Mediators in the Relationship between Attachment Styles and Sexual Function. The Development of Psychology, 1, 51-64.

Besharat, M. A., Nadali, H., Zarbast, A., \& Salehi, M. (2008). Perfectionism and Stress Coping Styles. Evolutionary Psychology (Iranian Psychologists), 5, 7-17.

Carr, A. (2000). Family Therapy. Concepts, Process and Practice. New York: Wiley.

Claire, M. K., Dush, M., \& Taylor, G. (2011). Trajectories of Marital Conflict across the Life Course: Predictors and Interactions with Marital Happiness Trajectories. Journal of Family Issues, 33, 341-368. 
Davari, N. (2013). Investigating the Relationship between Mental Well-Being and Job Performance and Quality of Life in Shahid Rajaee Port Workers. Master's Thesis, Hormozgan: Islamic Azad University.

Fowers, B. J., \& Olson, D. H. (1992). Four Types of Premarital Couples: An Empirical Typology Based on PREPARE. Journal of Family Psychology, 6, 10-21. https://doi.org/10.1037/0893-3200.6.1.10

Grossifarshi, M., Mani, A., \& Bakhshiipour, A. (2006). Investigating the Relationship between Personality Characteristics and Happiness among Students of Tabriz University. Quarterly Journal of Psychology, University of Tabriz, 1, 143-158.

Halford, W. K. (2001). Brief Couple Therapy for Couple. New York: Guilford Publications.

HosseiniSedeh, S. M., \& FathiAshtiani, A. (2011). Investigating the Relationship between Marital Satisfaction and Marriage Duration among Students at Imam Khomeini Institute of Education and Research. Ravanshenasi-va-Din, 3, 127-145.

Karami, J., Zakiei, A., Alikhani, M., \& Khodadadi, K. (2012). Relationship between Life Skills and Marital Conflicts with Mental Health in Couples. Family Counseling and Psychotherapy, 1, 461-472.

Karimi, T., Rangrazian, F., \& Mobasheramini, Z. (2016). The Effect of Stress Coping Strategies on Marital Satisfaction and Parental Stress in Mentally Infant Children. Mental Health of the Child, 3, 107-111.

Kraskian Mojambari, A., \& Kiba Divine, T. (2014). Compilation and Standardization of Gender Function Questionnaire in Married Women in Tehran. New Care, 11, 44-54.

Lazarus, R. S., \& Folkman, S. (1984). Stress, Appraisal, and Coping. New York: Springer.

Lazarus, R. S., \& Folkman, S. (1986). Cognitive Theories of Stress and the Issue of Circularity. In M. H. Appley, \& R. Trumbull (Eds.), Dynamics of Stress. Physiological, Psychologcal, and Social Perspectives (pp. 63-80). New York: Plenum.

Lyubomirsky, S. (2001). Why Are Some People Happier Than Others?: The Role of Cognitive and Motivational Processes in Well-Being. American Psychologist, 56, 239-249. https://doi.org/10.1037/0003-066X.56.3.239

Markman, H. J., \& Halford, W. K. (2005). International Perspectives on Couple Relationship Education. Family Process, 44, 139-146. https://doi.org/10.1111/j.1545-5300.2005.00049.x

Navabinejad, S., Dokaneifard, F., \& Aghajani, F. (2009). Investigating the Relationship between Attachment Style and Happiness with Marital Satisfaction of Married Women Employed in Khatamalanbia Hospital in Tehran. Woman and Family Studies, 2, 121-149.

Patrik, S., Sells, J., Giordano, F., \& Tollerud, T. (2007). Intimacy, Differentiation and Personality Variables as Predictor of Marital Satisfaction. The Family Journal, 15, 359-367. https://doi.org/10.1177/1066480707303754

Pico, B. (2001). Gender Differences and Similarities in Adolescents' Ways of Coping. The Psychological Record, 51, 223-263. https://doi.org/10.1007/BF03395396

Pressman, S. D., \& Cohen, S. (2005). Does Positive Affect Influence Health? Psychological Bulletin, 131, 925-971. https://doi.org/10.1037/0033-2909.131.6.925

Rajabi, G., \& Ghaffari, M. (2008). Sexual Misfunction in Women (Etiology, Diagnosis and Treatment). New Psychotherapy, 13, 20-38.

Rosen, R. C., Brown, C., Heiman, J., Leiblum, S., Meston, C., Shabsigh, R., \& D’Agostino, R. (2000). The Female Sexual Function Index (FSFI): A Multidimensional Self-Report Instrument for the Assessment of Female Sexual Function. Journal of Sex and Marital 
Therapy, 26, 191-208. https://doi.org/10.1080/009262300278597

Rostami, A. M. (2012). Comparison of Coping Styles in Patients with Cancer, Multiple Sclerosis (MS) and Normal Individuals. Graduate Thesis, Tehran: Islamic Azad University of Roudehen Branch.

Rostami, A. M., Ahadi, H., \& Cheraghaligol, H. (2013). The Prediction of Coping Strategies Based on Personality Traits in Irritants Affiliates. Research on Addiction, 7, 111-126.

Sanaei, B., Hooman, A., \& Alaghmand, S. (2009). Family and Marriage Measurement Scales. Tehran: Besat Publications.

Sarafino, E. P. (2002). Health Psychology (4th ed.). New York: John Wiley and Sons.

Satir, V. M. (1967). Conjoint Family Therapy. Palo Alto, CA: Science and Behavior Books.

Sepehrian Azar, F., Mohammadi, N., Badalpour, Z., \& Norouzadeh, V. (2016). Relation of Hope and Happiness with Marital Satisfaction. Health and Care, 18, 37-44.

Shahverdi, J., Rezaei, M., Ayazi Roozbehani, M., Sadeghi, K., Bakhtiyari, M., \& Shahverdi, M. (2015). The Relationship between General Health and Happiness, Feelings of Humiliation and Marital Conflicts in Infertile Women in Boroujerd. Journal of Nursing and Midwifery Faculty, Shaheed Beheshti University of Medical Sciences, No. 90, 31-54.

Sharif, N., \& Yousefi, A. (2015). The Relationship between Cognitive Impairment of Interleukin-6 and Cognitive Impairment in Coronary Heart Disease Patients When Exposed to a Stressful Event. Journal of Sabzevar University of Medical Sciences, 22, 1088-1098.

Sheikholeslami, R., Nejati, E., \& Ahmadi, S. (2011). The Prediction of Happiness Components of Married Women through Self-Esteem and Marital Relationships. Woman in Culture and Arts (Women's Research), 3, 37-52.

Shirazi, M. T., Taheri, M., \& Bagheri, G. (2015). Relationship of Stress Coping Methods with Happiness among Female Students in Zabol. Journal of Zabol University of Medical Sciences \& Health Services, 7, 1-10.

Siffert, A., \& Schwarz, B. (2010). Spouses' demand and Withdrawal during Marital Conflict in Relation to Their Subjective Well-Being. Journal of Social and Personal Relationships, 28, 262-277. https://doi.org/10.1177/0265407510382061

Soudani, M., ShafiAbadi, A., Etemadi, A., \& Delavar. (2009). Comparison of the Effectiveness of Dyshizar's Solutions-Focused Therapy in Individual and Cooperative Combination in Reducing Marital Conflict. Educational Psychology (Psychology and Educational Sciences), 5, 39-54.

Troxel, W. M. (2006). Marital Quality, Communal Strength, and Physical Health. Ph.D. Thesis, Pittsburgh, PA: University of Pittsburgh, 16-25.

Vermillion, S. T. S., \& Holmes, M. M. (1997). Sexual Dysfunction in Women. Primary Care Update for $O B / G Y N S$, 4, 234-240. https://doi.org/10.1016/S1068-607X(97)00104-2

Watson, D., Clark, L. A., \& Tellegen, A. (1988). Development and Validation of Brief Measures of Positive and Negative Affect: The PANAS Scales. Journal of Personality and Social Psychology, 54, 1063-1070. https://doi.org/10.1037/0022-3514.54.6.1063

Zeinali, S. (2014). Investigating the Relationship between the Gender and Rectangular Schemes with Marital Burning in Married Students. In The First National Conference on Sustainable Development in Educational Sciences and Psychology, Social and Cultural Studies. 


\section{Appendix 1: Female Sexual Function Index}

The present questionnaire assesses your sexual emotions and responses within the past four weeks. Please try to answer the questions honestly to the maximum extent possible. Be sure that your responses will be kept confidential.

Please tick only one blank space for each question. You intended answer should be marked by drawing a circle inside the blank space.

\begin{tabular}{|c|c|c|c|c|c|c|c|}
\hline Row & Question & $\begin{array}{c}\text { Almost } \\
\text { always }\end{array}$ & $\begin{array}{l}\text { Most } \\
\text { often }\end{array}$ & Sometimes & $\begin{array}{l}\text { A few } \\
\text { times }\end{array}$ & $\begin{array}{c}\text { Almost } \\
\text { never }\end{array}$ & Never \\
\hline
\end{tabular}

1. How often have you been willing to have sexual activity during the past four weeks?

2 How intense has been your tendency to have sexual activity during the past four weeks?

3 How often did you feel sexually aroused during the sexual activity (turned on) over the past four weeks?

4 How intense has your sexual arousal (turn on) been during the sexual activity over the past four weeks

5 How often have you been sure during the past four weeks that you will become sexually aroused (turned on) in the course of sexual activity?

6 How often have you felt being satisfied with the sexual arousal (turned on) with your sexual intercourses during the past four weeks?

7 How often have you become lubricated (wet) in the course of sexual activity during the past four weeks?

How often have you found it difficult to get lubricated (wet) during the sexual activity over the past four weeks?

How often have you found yourself still lubricated (wet) even after the termination of the sexual activity during the past four weeks?

How often have you found it difficult to keep yourself lubricated (wet)

10 even after the termination of the sexual activity during the past four weeks?

11 How often have you felt orgasm (peak of sexual pleasure) during the sexual activity over the past four weeks?

12 How often have you found it difficult to reach orgasm (climax) during the sexual activity over the past four weeks?

13 How often have you been satisfied with reaching orgasm (climax) during the sexual activity over the past four weeks?

How often have you found yourself satisfied with the emotional

14 closeness to your husband during the sexual activity over the past four weeks?

15 How often have you found yourself satisfied with having sex with your husband during the past four weeks?

16 How often have you felt being satisfied in total with your sexual intercourse during the past four weeks?

How often have you experienced pain or discomfort during sexual intercourse over the past four weeks?

How often have you experienced pain and discomfort right after and following the sexual intercourse? 


\section{Appendix 2: Lazarus and Folkman's Coping Strategies Questionnaire (WCQ)}

Read through the below-mentioned behaviors and reactions and make it clear how often you use these methods when stressed and mark your response in a range from 0 to 3 below:

$0=$ never; $1=$ to some extent; 2 = most of the time; and, 3 = quite often

1) I only paid attention to what I had to carry out in the next stage.

2) I did my best to analyze the issue so as to better understand it.

3) To distract my mind from these thoughts, I kept myself busy with the works or activities of the others.

4) I felt that the passage of time will bring about a change and I only have to only wait.

5) I started negotiation and compromise so as to reach a positive result of the situation.

6) I did something that was not deemed effective, but I had at least done something.

7) I did my best to make the official in charge change his mentality.

8) I spoke with another person to figure out the situation.

9) I criticized and reproached myself.

10) I was looking for solutions while keeping the retreat way open.

11) I was hoping for a miracle.

12) I always accept my destiny and I sometimes know myself as an unlucky person.

13) I pretended that nothing has happened.

14) I did my best to keep my feelings hidden from the others.

15) I was optimistic in such a way that I did my best to imagine something positive in my conversations.

16) I slept more than usual.

17) I expressed my anger towards the individual(s) who had caused the problem.

18) I accepted the others' sympathy and consultation.

19) I used to tell myself things that made me feel better.

20) It suddenly dawned on me to do something more of a creative nature in regard of this problem.

21) I did my best to forget everything.

22) I asked assistance of an expert.

23) I changed and evolved like a human being.

24) Before doing anything, I waited to see what may come about.

25) I apologized or did something to compensate it.

26) I planned something and implemented it.

27) When I found myself failed in accomplishing my primary objective, I chose the next nearest goal.

28) I let my feelings out one way or another.

29) I found out that I myself have caused the problem.

30) After this experience, I was better than before.

31) I spoke to another person who could do some real thing about the problem.

32) I tried getting rid of the problem by going on vacation or resting.

33) I tried eating, drinking, smoking, narcotics use or drugs to make myself feel better.

34) I either turned out very lucky or did something risky to solve the problem.

35) I decided not to act hurriedly or not to follow my first thought.

36) I found a new faith.

37) I behaved proudly and pretended nothing has happened.

38) I have just found out what is important in life.

39) I changed the affairs so as to make everything look right. 
40) I generally avoided being with the people.

41) I did not allow the issue keep me engaged and avoided thinking too much about it.

42) I asked a respectable friend or relative to advise me.

43) I did not let the others figure out how bad has been the problem.

44) I took the issue easy and avoided taking it overly serious.

45) I spoke with someone about how I felt.

46) I did not retreat and fought for what I wanted.

47) I blamed the others for the issue.

48) I reviewed my past experiences; I had been in a similar situation before.

49) I knew what to do so I doubled my efforts.

50) I denied believing in what had happened.

51) I assured myself that next time everything will be different.

52) I devised two different solutions to solve the problem.

53) I accepted the situation finding out that nothing could be done.

54) I tried not allowing other things interfere with my feelings about this problem.

55) I wished I could change the way I felt and/or what had happened.

56) I changed some things in myself.

57) I had a better dream and temporal or spatial imagination of what I was really in.

58) I wished I could somehow get past the situation or it could be solved.

59) I used to fantasize about what might happen and I had wishes about it.

60) I prayed.

61) I had prepared myself for the worst.

62) I reviewed what I wanted to say or do in my brain.

63) I thought how a person whom I admire faces the situation and I took him as a role-model.

64) I did my best to approach the issue from the perspective of the others.

65) I kept reminding myself that how worse it could have become.

66) I did stretching or played sports. 


\section{Appendix 3: Mental Happiness Questionnaire (PANAS)}

The present scale includes some terms describing the different feelings and emotions. Please, read through the statements one by one and make it clear that, in general, to what extent you usually experience each of the following emotions. Then write down your intended answer number in the blank space beside the term. To score your answers, use the following guide scale:

Very much, much, intermediate, a little, not at all
-

